\title{
Investigation of a Cloud- Cover Modification to SPCTRAL2, SERI'S Simple Model for Cloudless-Sky, Spectral Solar Irradiance
}

\author{
R. E. Bird \\ C. J. Riordan \\ D. R. Myers
}

June 1987

Prepared under Task No. 6001.20

FTP No. 594A

Solar Energy Research Institute

A Division of Midwest Research Institute

1617 Cole Boulevard

Golden, Colorado 80401-3393

Prepared for the

U.S. Department of Energy

Contract No. DE-AC02-83CH10093 


\section{NOTICE}

This report was prepared as an account of work sponsored by the United States Government. Neither the United States nor the United States Department of Energy, nor any of their employees, nor any of their contractors, subcontractors, or their employees, makes any warranty, expressed or implied, or assumes any legal liability or responsibility for the accuracy, completeness or usefulness of any information, apparatus, product or process disclosed, or represents that its use would not infringe privately owned rights.

Printed in the United States of America

Available from:

National Technical Information Service

U.S. Department of Commerce

5285 Port Royal Road

Springfield, VA 22161

Price: Microfiche A01

Printed Copy A03

Codes are used for pricing all publications. The code is determined by the number of pages in the publication. Information pertaining to the pricing codes can be found in the current issue of the following publications. which are generally available in most libraries: Energy Research Abstracts. (ERA): Government Reports Announcements and Index (GRA and I): Scientific and Technical Abstract Reports (STAR): and publication. NTIS-PR-360 available from NTIS at the above address. 


\section{PREFACE}

This report describes research performed by SERI's Resource Assessment and Instrumentation Branch to develop a cloud-cover modification to SERI's simple model for cloudless-sky spectral solar irradiance (SPCTRAL2). This research is part of a continuing effort to develop and verify spectral-solar-irradiance models and to build a spectral-irradiance data base for different locations and climates.

This work was sponsored by the United States Department of Energy (DOE). The authors thank Dave Menicucci, Sandia National Laboratory, Albuquerque; C. R. Nagaraja Rao, NOAA/NESDIS, Washington, D.C.; and Alfred M. Powe11, Jr., USAF, offutt AFB, Nebraska, for their useful review and comments.

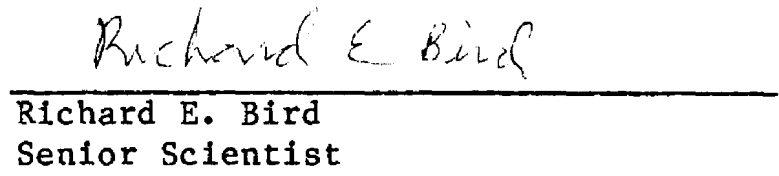

Approved for

SOLAR ENERGY RESEARCH INSTITUTE

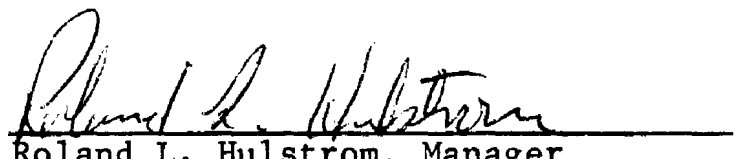

Roland L. Hulstrom, Manager

Resource Assessment and Instrumentation Branch

Jaek L. Stone, Director

Solar Electric Research Division 


\section{SUMMARY}

\section{Objective}

The objective of this research was to investigate a cloud-cover modification to SERI's simple model for cloudless-sky, spectral solar irradiance (SPCTRAL2). This work contributes to an ongoing effort in SERI's Resource Assessment and Instrumentation Branch to develop and verify spectralirradiance models that can be used, with measurements, to build a spectralsolar-irradiance data base for different locations and climates.

\section{Discussion}

Our approach was to investigate a modification to SPCTRAL2 that did not require detailed input on cloud properties, but relied on more commonly acquired meteorological and broadband data available in a historical data base (SOLMET). The method was to normalize modeled, cloudless-sky, spectral irradiance to a measured broadband-irradiance value under cloudy skies; and compare normalized, modeled data with measured spectral-irradiance data to empirically derive spectral modifiers that improve the agreement between modeled and measured data.

\section{Conclusions}

Results indicate the possible form of the spectral corrections; however, we must analyze additional data to develop a spectral transmission function for cloudy-sky conditions. 
TABLE OF CONTENTS

$\underline{\text { Page }}$

1.0 Introduction $\ldots \ldots \ldots \ldots \ldots \ldots \ldots \ldots \ldots \ldots \ldots \ldots \ldots \ldots \ldots \ldots \ldots \ldots$

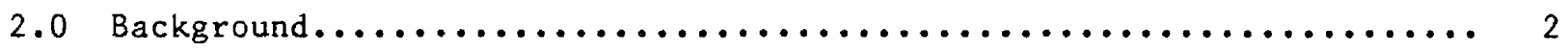

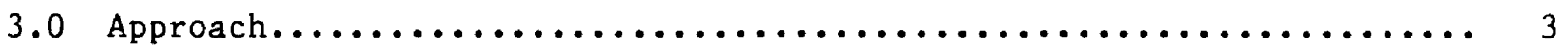

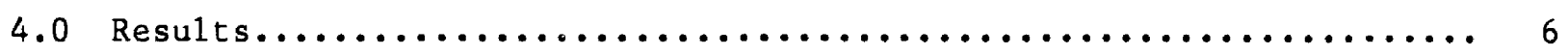

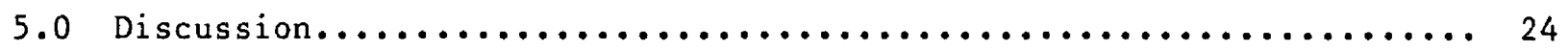

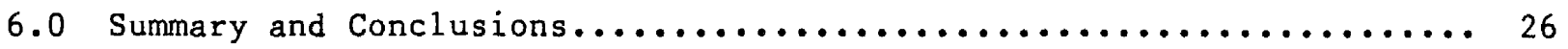

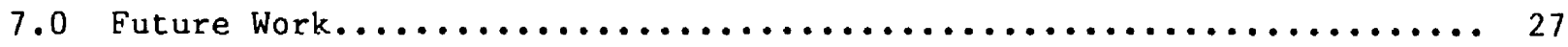

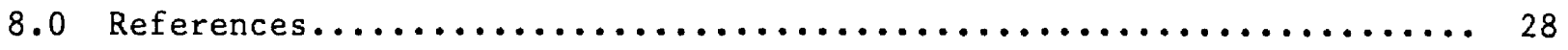




\section{LIST OF FIGURES}

4-1 Case 1. Comparison of Modeled and Measured Global-Normal (a) and Global-Horizontal (b) Spectral Solar Irradiance, and Photograph of Sky Conditions (solar zenith angle $=28.9^{\circ}$, relative optical air mass $=1.14) \ldots \ldots \ldots \ldots \ldots \ldots \ldots \ldots \ldots$

4-2 Case 2. Comparison of Modeled and Measured Globa1-Normal (a) and Global-Horizontal (b) Spectral Solar Irradiance, and Photograph of Sky Conditions ( relative optical air mass $=1.15) \ldots \ldots \ldots \ldots \ldots \ldots \ldots \ldots \ldots \ldots$

4-3 Case 3. Comparison of Modeled and Measured Global-Normal (a) and Global-Horizontal (b) Spectral Solar Irradiance, and Photograph of Sky Conditions (solar zenith angle $=43.7^{\circ}$,

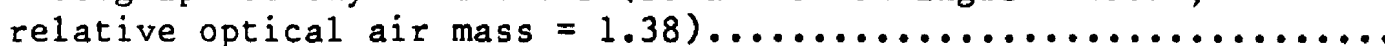

4-4 Case 4. Comparison of Modeled and Measured Global-Normal (a) and Global-Horizontal (b) Spectral Solar Irradiance, and Photograph of Sky Conditions (

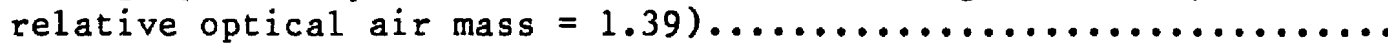

4-5 Case 5. Comparison of Modeled and Measured Global-Normal (a) and Global-Horizontal (b) Spectral Solar Irradiance (solar zenith angle $=27.9^{\circ}$, relative optical air mass $\left.=1.13\right) \ldots \ldots \ldots$

4-6 Case 6. Comparison of Modeled and Measured Global-Normal (a) and Global-Horizontal (b) Spectral Solar Irradiance, and Photograph of Sky Conditions ( relative optical air mass $=1.32) \ldots \ldots \ldots \ldots \ldots \ldots \ldots \ldots \ldots \ldots \ldots$

4-7 Case 7. Comparison of Modeled and Measured Global-Normal (a) and Global-Horizontal (b) Spectral Solar Irradiance, and Photograph of Sky Conditions (

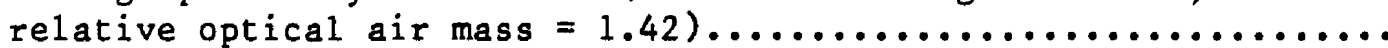

4-8 Case 8. Comparison of Modeled and Measured Direct-Normal (a) and Global-Horizontal (b) Spectral Solar Irradiance (solar zenith angle $=56.0^{\circ}$, relative optical air mass $\left.=1.78\right) \ldots \ldots \ldots \ldots$

4-9 Case 9. Comparison of Modeled and Measured Direct-Normal (a) and Global-Normal (b) Spectral Solar Irradiance, and Photograph of Sky Conditions (solar zenith angle $=28.0^{\circ}$, relative optical

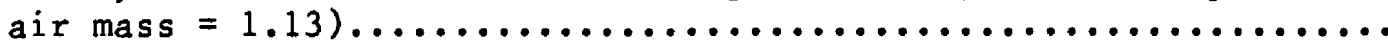

4-10 Case 10. Comparison of Modeled and Measured Direct-Normal (a) and Global-Norma1 (b) Spectral Solar Irradiance, and Photograph of Sky Conditions ( solar zenith angle $=32.8^{\circ}$, relative optical

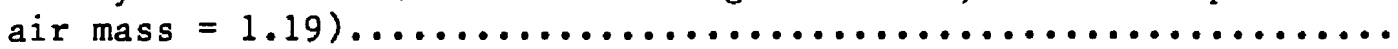


LIST OF FIGURES (Concluded)

$\underline{\text { Page }}$

4-11 Case 11. Comparison of Modeled and Measured Global-Normal

Spectral Irradiance, and Photograph of Sky Conditions (solar zenith angle $=30.7^{\circ}$, relative optical air mass $\left.=1.16\right) \ldots \ldots \ldots 20$

4-12 Case 12. Comparison of Modeled and Measured Global-Normal (a) and Global-Horizontal (b) Spectral Solar Irradiance, and Photograph of Sky Conditions ( relative optical air mass $=1.21$ )

4-13 Case 13. Comparison of Modeled and Measured Global-Norma1 (a) and Global-Horizontal (b) Spectral Solar Irradiance, and Photograph of Sky Conditions ( relative optical air mass $=1.39) \ldots \ldots \ldots \ldots \ldots \ldots \ldots \ldots \ldots \ldots$

4-14 Case 14. Comparison of Modeled and Measured Global-Normal (a) and Global-Horizontal (b) Spectral Solar Irradiance, and Photograph of Sky Conditions ( relative optical air mass $=1.50) \ldots \ldots \ldots \ldots \ldots \ldots \ldots \ldots \ldots$

\section{LIST OF TABLES}

3-1 Measurements and Documentation for Each Spectral-Irradiance Data File..................................... 4

4-1 Description of Measured Spectra in Figures 4-1 through 4-14...... 8

4-2 Difference Between Modeled and Measured Irradiance below $0.55 \mu \mathrm{m}$ for Cases 1 and $5 \ldots \ldots \ldots \ldots \ldots \ldots \ldots \ldots \ldots \ldots . \ldots . \ldots . \ldots$

5-1 Measurement Uncertainty for Cloudless-Sky Conditions.......... 25 


\subsection{INTRODUCTION}

This report documents research performed during fiscal year (FY) 1986 by SERI's Resource Assessment and Instrumentation Branch to extend SPCTRAL2, SERI's simple model for spectral solar irradiance for cloudless-sky conditions [1,2], to include cloudy conditions. This effort was included in FY 1986 activities under the Resource Assessment Project's (RAP) Solar Radiation Models task, in response to the needs expressed by the solar community [3-5]. The specific need is for spectral-solar-irradiance data representing a range of outdoor conditions for cloudless, partly cloudy, or overcast skies. Our practical approach to obtain these data is to first develop models such as SPCTRAL2 that predict solar resource characteristics from available meteorological-type data, and then combine modeled and measured data into a spectral-irradiance data base. 


\subsection{BACKGROUND}

Our objective is to modify SERI's current model for cloudless-sky conditions, SPCTRAL2, to account for the influence of clouds on total irradiance and spectral distribution. Details about the SPCTRAL2 model and its development are found in various reports $[1,2,6]$. Briefly, the code calculates direct and diffuse irradiance on horizontal and tilted planes at the earth's surface, at 122 wavelengths ranging from 0.3 to $4.0 \mu \mathrm{m}$, with a resolution of approximately $0.01 \mu \mathrm{m}$. Inputs to the model are solar zenith angle, collector-tilt angle, atmospheric turbidity, precipitable water, surface pressure, and ground albedo. This code was developed using comparisons with rigorous radiative transfer codes and limited outdoor measurements. The intent was to provide a simple, approximate model that could be used by the solar community to calculate spectral solar irradiance using small computers and minimal input.

Validation and verification of SPCTRAL2 is ongoing in SERI's Resource Assessment and Instrumentation Branch. Comparisons of modeled and measured data for a limited set of cloudless-sky conditions indicate that SPCTRAL2 produces spectra that agree with measured data to within $10 \%$ in the ultraviolet region, $5 \%$ in the visible region, and $6 \%$ in the near-infrared region of the spectrum [7]. An uncertainty analysis of the measurement instrumentation results in an uncertainty of approximately $6 \%$ in the ultraviolet region, $7 \%$ in the visible region, and $10 \%$ in the near-infrared region. Hence, in view of these instrument uncertainties, SPCTRAL2 modeled data compare favorably with measured data. 


\subsection{APPROACH}

Our approach to developing a cloud-cover modifier for SPCTRAL2 was to begin with the hypothesis that clouds act as a wavelength-independent filter on cloudless-sky solar spectra. We would then derive spectral (wavelengthdependent) modifiers, if warranted, to obtain closer agreement between measured and modeled data. Support for the initial hypothesis is found in Deirmendjian [8]; Guzzi, Vittori, and Tomasi [9]; and Feigelson [10], We also imposed the constraint that the cloud-cover modifier would not require detailed input on cloud properties (structure, composition, etc.), but that it would rely on more commonly acquired meteorological and broadband solarradiation data that are available in a historical data base (SOLMET) [11]. Besides, the limited data available on detailed cloud physics for input to a model do not warrant the development of a complex cloud-cover modifier in this case. This was illustrated by Powel1 [12] in his attempt to produce a model using a fairly complex set of input data. The input data were not available to verify his model and would not be available on a routine basis.

The procedure for acquiring spectral-irradiance and supporting data to develop the cloud-cover modifier is specified in the Resource Assessment Project's plan for collecting spectral-solar-irradiance data [13]. This plan describes the recommended broadband solar-radiation data, meteorological data, and other information that should be recorded with each measured spectrum to adequately document the atmospheric conditions and solar geometry during each measurement (see Table 3-1). The major factors that determine the spectral distribution, such as atmospheric turbidity, are recorded so that the spectral-irradiance data can be extended to other locations with similar, observable outdoor conditions.

An explanation of the data-collection philosophy is given in the previously mentioned plan; however, two of the more important points are given here. First, the measurements and data 1isted in Table 3-1 allow us to calculate some important descriptors of atmospheric conditions, such as atmospheric transmittance of direct-beam and total solar irradiance (which are related to cloud cover), atmospheric turbidity, and precipitable water vapor. Some of the parameters in Table 3-1 provide redundant or correlated information, such as relative humidity and precipitable water vapor, to provide cross checking and the option of using more readily available data.

The second important point is the total irradiance stability check during the $30 \mathrm{~s}$ that is required to obtain a spectral scan with the spectroradiometers, which is especially important under cloudy conditions. A pyranometer with a silicon detector (for millisecond time response) monitors total solar irradiance during each spectral-irradiance measurement; if the irradiance deviates by more than a preset amount, the scan is aborted. The purpose of this check is to avoid distorted spectral distributions caused by variations in total solar intensity from cloud movement and changes. We started with a cutoff of $\pm 5 \%$ but found that we could obtain a reasonable number of spectra and avoid spectral distortion by using a cutoff of $\pm 2 \%$. We also took an all-sky (fisheye) photograph to record cloud distribution and amount during each spectralirradiance scan. 
Table 3-1. Measurements and Documentation for Each Spectral-Irradiance Data File

Site identifier (1atitude/longitude) ${ }^{a}$

Date (day number/year) ${ }^{a}$

Local standard time (hours/minutes) ${ }^{a}$

Collection mode for spectral-irradiance scan (e.g., global horizontal, direct normal)

Direct-normal broadband irradiance $\left(W \mathrm{~m}^{-2}\right)^{b}$

Direct-normal broadband irradiance--silicon detector $\left(\mathrm{W} \mathrm{m}^{-2}\right)^{\mathrm{b}, c}$

Global-horizontal broadband irradiance $\left(\mathrm{W} \mathrm{m}^{-2}\right)^{b}$

Global-horizontal broadband irradiance--silicon detector $\left(\mathrm{W} \mathrm{m}^{-2}\right)^{\mathrm{b}, c}$ Global (total) broadband irradiance on a surface normal to the direct beam

Global (total) broadband irradiance on a surface tilted at a specified angle (usually south-facing at tilt = latitude) $\left(\mathrm{W} \mathrm{m}^{-2}\right)$

Ground albedo (\%)

Relative humidity (\%)

National Weather Service precipitable water vapor $(\mathrm{cm})$

Ambient temperature $\left({ }^{\circ} \mathrm{C}\right)$

Surface pressure (millibars)

Average wind speed (mph)

Opaque cloud cover (tenths) and/or all-sky photograph

Multiwavelength sun photometer values (at $0.380,0.500,0.862$, and $0.940 \mu \mathrm{m}$ ) Spectral irradiance $\left(\mathrm{W} \mathrm{m} \mathrm{m}^{-2}\right.$ or equivalent) $\mathrm{e}^{-1}$

Operator comments

${ }^{a}$ Location, date, and time are used to calculate solar zenith angle and relative optical air mass.

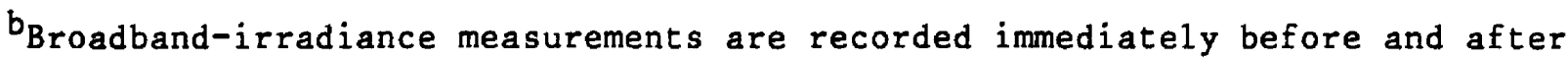
the spectral-irradiance scan to evaluate atmospheric stability.

${ }^{c}$ Instruments with silicon detectors have a fast time response and are used to monitor atmospheric stability during the spectral-irradiance scan.

${ }^{d}$ spectral measurements at these wavelengths are made with sun photometers with narrow-band filters, and the values are used to calculate atmospheric turbidity and precipitable water vapor.

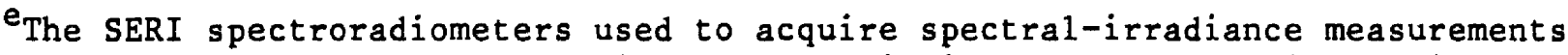
reported here have the following characteristics: a holographic grating monochromator, a wavelength range of 0.300 to $1.100 \mu \mathrm{m}$, a bandwidth of $0.006 \mu \mathrm{m}$, a user-selectable scan step size, and a total scan time of $27 \mathrm{~s}$ at the $0.002-\mu \mathrm{m}$ step size. SERI modified these spectroradiometers by adding (1) integrating spheres, which improve the cosine/azimuth response of the instruments for measuring off-normal global irradiance; (2) direct-beam modules with a $5^{\circ}$ field of view and which are used for measuring directnormal spectral irradiance; and (3) temperature controllers to account for the temperature dependence of the detector response. The instruments are calibrated against standard lamps that are traceable to the National Bureau of Standards [14]. 
The sun photometer measurements that are used to derive turbidity are obtained only when the sun's disk is clearly visible (i.e., a cloudless line of sight). The sun photometer data can also be used to derive precipitable water vapor; however, we used values reported by the National Weather Service and the Wave Propagation Laboratory in the Radio Meteorology Program of the National Oceanic and Atmospheric Administration (NOAA) in Boulder, Colo.

Our procedure for developing the cloud-cover modifier for SPCTRAL2 was as follows:

- Calculate cloudless-sky spectral irradiance using SPCTRAL2 and the input parameters, such as day of the year and time of day, corresponding to the spectral-irradiance measurements (see Table 3-1).

- Normalize the cloudless-sky, modeled spectra to the appropriate measured broadband-irradiance value to account for differences in bulk atmospheric transmittance under cloudy-sky conditions.

- Compare the normalized modeled data with the measured data (spectral plots) and derive empirical expressions (spectral modifiers) that improve the agreement between modeled and measured data.

The broadband solar-irradiance measurements acquired during the spectral scan are critical for evaluating the impact of clouds on total transmittance and testing the initial assumption of a wavelength-independent filter. Two of these measurements, total (global)-horizontal (GH) and direct-normal (DN) solar irradiance, are recorded in the national solar radiation measurement network [11] and fit the criterion of readily available input data for solarirradiance models. Therefore, these two values were selected as the only additional input requirements for modifying SPCTRAL2 to account for cloudcover effects. This will allow, if successful, the SOLMET and similar broadband data bases to be converted to a spectral-solar-irradiance data base. 


\subsection{RESULTS}

Since we began with the assumption of clouds as being wavelength-independent filters, the first step in the cloud-cover modifier is to compare the integral under the modeled-spectral-irradiance curve with measured broadband-irradiance values to evaluate total atmospheric transmittance. The model calculates $\mathrm{GH}$ spectral irradiance, integrates this irradiance, and compares the integral to a $\mathrm{GH}$ broadband measurement. If the values differ by 1 ess than $5 \%$, no cloudcover modifications are applied to the cloudless-sky spectrum.

The $5 \%$ criterion is an arbitrary value based on measurement uncertainty $[14,15]$ and the accuracy of the cloudless-sky model determined from previous evaluations [7]. The 5\% criterion also allows for small errors in the input to the model, such as atmospheric turbidity and precipitable water vapor. The uncertainty in the modeled results is difficult to evaluate since turbidity and water-vapor measurements with a sun photometer are not obtained when clouds obscure the sun's disk. In this case, we use values for previous or subsequent cloudless-sky periods. Since the range in turbidity and water-vapor values for the five days in the data set is small, we do not expect large errors in the modeled data due to incorrect values for these two parameters. A change in turbidity has little effect in the infrared region of the spectrum and the largest effect in the ultraviolet region. A change in precipitable water affects only those regions where water-vapor absorption occurs, and these regions are concentrated in the infrared region. An error in either of these quantities will cause the modeled spectra to be skewed when the normalization is invoked.

If the integrals differ by more than $5 \%$, both the DN and $G H$ spectra are normalized to the measured broadband values for DN and $\mathrm{GH}$ solar irradiance, respectively, using the equations

$$
I(\lambda)=\frac{I_{G H, \text { meas }}}{\int_{0.3}^{4.0 \mu m} I(\lambda) \text { GH, mod } d \lambda} \mathrm{GH, \operatorname {mod }}
$$

and

$$
I(\lambda)=\frac{I_{D N}, \text { meas }}{\int_{0.3}^{4.0 \mu m} I(\lambda),{ }_{D N}, \bmod } d \lambda \text { DN, mod },
$$

where $I_{G H}$, meas and $I_{D N}$, meas are measured $G H$ and $D N$ broadband-irradiance values, respectively, and $I(\lambda)$, mod ${ }_{\mathrm{GH}}(\lambda)$, mod are cloudless-sky $G H$ and $D N$ spectra modeled using SPCTRAL2. The model then proceeds to calculate diffuse, direct, and total (global) spectral solar irradiance on the collector surface, which can be oriented in any direction.

We empirically derived two spectral modifiers that improve the agreement between measured and modeled data when the cloud modification is invoked. 
First, modeled diffuse irradiance on the collector surface is increased for wavelengths less than or equal to $0.55 \mu \mathrm{m}$ using the expression

$$
\text { Diffuse } x(\lambda+0.45)^{-1.0} \text {, }
$$

where $\lambda$ is wavelength in units of $\mu \mathrm{m}$.

The maximum increase using this expression is one-third of the diffuse irradiance at $0.3 \mathrm{\mu m}$. The second modification is the addition of a constant $7 \%$ to the diffuse spectral irradiance at each wavelength from 0.50 to $0.926 \mu \mathrm{m}$. We did not evaluate the model beyond $1.1 \mu \mathrm{m}$, since this is the wavelength 1 imit of the spectroradiometer used in our measurements.

Comparisons of measured and modeled spectral irradiance using SPCTRAL2 with the cloud-cover modifier are shown in Figures 4-1 through 4-14. Two spectra were measured simultaneously in 13 of the cases using two spectroradiometers, along with the supporting information given in Table 3-1. Measured data were acquired from 0.35 to $1.1 \mu \mathrm{m}$ with a $0.01-\mu \mathrm{m}$ step size on days 108,111 , and 112. On day 115, DN data were acquired from 0.3 to $1.1 \mu \mathrm{m}$, and global data were acquired from 0.35 to $1.1 \mu \mathrm{m}$ with a $0.002-\mu \mathrm{m}$ step size. On day 210 , all data were measured from 0.3 to $1.1 \mu \mathrm{m}$ with a $0.002-\mu \mathrm{m}$ step size.

Table 4-1 lists the day number, solar zenith angle, relative optical air mass, surface pressure, precipitable water vapor, turbidity, ground albedo, and spectroradiometer modes, and also the ratio of measured GH and DN broadband irradiance to integrated cloudless-sky, modeled spectral irradiance for each measured spectrum. We used the $\mathrm{GH}$ ratios in the model to normalize the modeled GH spectra, and we used the DN ratios to normalize the modeled DN in cases where the cloud-cover modification was invoked.

A strong direct-beam component was present (DN ratio greater than 0.60 ) in 8 of the 13 cases (see Table 4-1), representing nearly cloudless to partlycloudy conditions. The cloud-cover modification was invoked in two of these cases ( 1 and 5 ) with the direct beam present. In case 5, the normalization resulted in an enhancement of the global cloudless-sky irradiance (GH ratio of 1.292). In both cases 1 and 5 , the modifications provided very good agreement between modeled and measured data (see Eigures 4-1 and 4-5) from 0.55 to $1.1 \mu \mathrm{m}$, and the model estimates are greater than measured irradiance below $0.55 \mu \mathrm{m}$, as shown in Table 4-2. In these two cases, with a strong direct beam present, the spectral modifier in the ultraviolet (UV)-visible region does not appear to improve the agreement between modeled and measured data.

A strong direct-beam component was present, and no normalization or spectral corrections were invoked in cases 4 and 6 through 10 . In three of these cases $(8,9$, and 10$)$, the DN spectral irradiance was measured; agreement between modeled and measured data was very good (see Figures 4-8 through 4-10) except for a small difference in the region from 0.45 to $0.65 \mu \mathrm{m}$. In this region, the modeled data are lower than the measured data by about $1 \%-7 \%$. This may be because the modeled data do not account for circumsolar radiation, whereas the measured data include circumsolar radiation in a $5^{\circ}$ field of view. The agreement between modeled and measured global normal (GN) data is within about $3 \%-5 \%$ in case 10 , which represents nearly cloudless conditions (some haze). 
Table 4-1. Description of Measured Spectra ${ }^{a}$ in Figures 4-1 through 4-14

\begin{tabular}{|c|c|c|c|c|c|c|c|c|c|c|}
\hline $\begin{array}{l}\text { Case } \\
\text { No. }\end{array}$ & $\begin{array}{l}\text { Day } \\
\text { No. }\end{array}$ & $\begin{array}{c}\text { Zenith } \\
\text { Angle } \\
\text { (deg) }\end{array}$ & $\begin{array}{l}\text { Air } \\
\text { Mass }\end{array}$ & $\begin{array}{c}\text { Surface } \\
\text { Pressure }\end{array}$ & $\begin{array}{c}\text { Precipitable } \\
\text { Water Vapor } \\
(\mathrm{cm})\end{array}$ & $\begin{array}{l}\text { Turbidity } \\
(0.5 \mu \mathrm{m})\end{array}$ & $\begin{array}{l}\text { Ground } \\
\text { A1 bedo } \\
(\%)\end{array}$ & $\begin{array}{l}\text { Spectro- } \\
\text { radiometer } \\
\text { Modes }\end{array}$ & GH Ratioc & DN Ratioc \\
\hline 1 & 108 & 28.9 & 1.14 & 815.8 & 0.56 & 0.103 & 18 & GN , GH & 0.948 & 0.686 \\
\hline 2 & 108 & 29.3 & 1.15 & 815.8 & 0.56 & 0.103 & 18 & $\mathrm{GN}, \mathrm{GH}$ & 0.327 & 0.003 \\
\hline 3 & 108 & 43.7 & 1.38 & 815.8 & 0.56 & 0.103 & 18 & GN, GH & 0.208 & 0.002 \\
\hline 4 & 111 & 44.1 & 1.39 & 813.3 & 1.31 & 0.088 & 18 & $\mathrm{GN}, \mathrm{GH}$ & 0.982 & 1.008 \\
\hline 5 & 111 & 27.9 & 1.13 & 819.4 & 1.39 & 0.088 & 18 & GN, GH & 1.292 & 0.997 \\
\hline 6 & 112 & 40.6 & 1.32 & 813.3 & 1.10 & 0.103 & 18 & GN , GH & 1.006 & 1.027 \\
\hline 7 & 112 & 45.4 & 1.42 & 813.3 & 1.10 & 0.103 & 18 & $\mathrm{GN}, \mathrm{GH}$ & 0.968 & 0.954 \\
\hline 8 & 115 & 56.0 & 1.78 & 810.5 & 0.50 & 0.110 & 20 & DN , GH & 0.960 & 1.012 \\
\hline 9 & 115 & 28.0 & 1.13 & 809.0 & 0.50 & 0.110 & 20 & DN, GN & 1.022 & 0.996 \\
\hline 10 & 210 & 32.8 & 1.19 & 822.2 & 1.00 & 0.080 & 18 & DN, GN & 0.970 & 1.024 \\
\hline 11 & 210 & 30.7 & 1.16 & 820.2 & 1.00 & 0.080 & 17 & GN & 0.312 & 0.002 \\
\hline 12 & 210 & 34.5 & 1.21 & 820.2 & 1.00 & 0.080 & 17 & GN , GH & 0.408 & 0.016 \\
\hline 13 & 210 & 43.9 & 1.39 & 819.6 & 1.00 & 0.080 & 17 & $\mathrm{GN}, \mathrm{GH}$ & 0.332 & 0.006 \\
\hline 14 & 210 & 48.4 & 1.50 & 819.6 & 1.00 & 0.080 & 18 & $\mathbf{G N}, \mathbf{G H}$ & 0.546 & 0.063 \\
\hline
\end{tabular}

${ }^{a}$ Spectra1-irradiance measurements obtained at Golden, Colo., $39.74 \mathrm{deg}$, $105.18 \mathrm{deg} . \mathrm{W}$, elevation $1828.8 \mathrm{~m}$.

${ }^{b_{G N}}=180^{\circ}$ field of view with aperture oriented normal to the direct beam (global normal).

$\mathrm{GH}=180^{\circ}$ field of view with aperture horizontal (global horizontal).

DN $=5^{\circ}$ field of view with aperture oriented normal to the direct beam (direct normal).

${ }^{c}$ Computed as in Eq. 4-1 and 4-2. 
Table 4-2. Difference Between Modeled and Measured Irradiance below $0.55 \mu \mathrm{m}$ for Cases 1 and 5

\begin{tabular}{|c|c|c|c|c|}
\hline \multirow{2}{*}{$\begin{array}{l}\text { Wavel ength } \\
(\mu \mathrm{m})\end{array}$} & \multicolumn{2}{|c|}{ Global Normal } & \multicolumn{2}{|c|}{ Global Horizontal } \\
\hline & $\mathrm{W} \mathrm{m}^{-2} \mu \mathrm{m}^{-1}$ & $\%$ & $\mathrm{~W} \mathrm{~m}^{-2} \mu \mathrm{m}^{-1}$ & $\%$ \\
\hline \multicolumn{5}{|l|}{ Case 1} \\
\hline 0.38 & 126 & 16.9 & 89 & 12.5 \\
\hline 0.42 & 103 & 7.8 & 94 & 7.8 \\
\hline 0.46 & 61 & 3.6 & 75 & 4.9 \\
\hline \multicolumn{5}{|l|}{ Case 5} \\
\hline 0.38 & 251 & 26.0 & 188 & 20.6 \\
\hline 0.42 & 245 & 13.7 & 210 & 13.0 \\
\hline 0.46 & 172 & 7.5 & 171 & 8.5 \\
\hline
\end{tabular}

However, in cases 8 and 9 the measured global irradiance is lower than modeled by about $3 \%-7 \%$ beyond $0.45 \mu \mathrm{m}$ in the $\mathrm{GH}$ case ( 8 ) and $8 \%-11 \%$ in the GN case (9).

In the $\mathrm{GN}$ and $\mathrm{GH}$ cases with no normalization and a strong direct-beam component $(4,6$, and 7$)$, agreement between modeled and measured data is very good (see Figures 4-4, 4-6, and 4-7). The largest difference is in the GN spectra of case 6 , in which the modeled data are lower than the measured data by $98 \mathrm{~W} \mathrm{~m}^{-2} \mu \mathrm{m}^{-1}(5.5 \%)$ at $0.55 \mu \mathrm{m}, 108 \mathrm{~W} \mathrm{~m}^{-2} \mu \mathrm{m}^{-1}(8 \%)$ at $0.74 \mu \mathrm{m}$, and $122 \mathrm{~W} \mathrm{~m}^{-2} \mu \mathrm{m}^{-1}(9.5 \%)$ at $0.78 \mu \mathrm{m}$.

The cloud-cover modifications (normalization and spectral corrections) were invoked in cases 2, 3, and 11-14. Both $\mathrm{GN}$ and $\mathrm{GH}$ spectra were modeled and measured for each of these cases. In all cases (except for the GN spectrum in case 3 , where the shape of the measured spectrum in the visible region indicates a possible problem with the instrumentation), the modeled data are somewhat lower than the measured, especially in the $0.45-1.1-\mu \mathrm{m}$ region (Figures 4-2, 4-3, and 4-11 through 4-14). However, since the spectral modifiers increase the modeled irradiance, they resulted in closer agreement between modeled and measured data. Agreement in case 12 (see Figure 4-12) is very good. In the other cases, agreement is generally within $5 \%-10 \%$ up to $0.7 \mathrm{\mu m}$, but deviates by about $15 \%-20 \%$ beyond $0.7 \mu \mathrm{m}$ in some cases. One feature in these cases that is present in all of the measured GN spectra, and to a lesser extent in the $\mathrm{GH}$ spectra, is an increased difference between modeled and measured data from 0.7 through $1.1 \mu \mathrm{m}$, especially at 0.74 and $0.78 \mathrm{~mm}$. Since this feature is more pronounced for the GN cases, a possible explanation is spectral ground albedo, which has not been taken into account in the model (a constant broadband value is used).

It is also apparent that water-vapor absorption is underestimated when the direct beam is obscured by clouds. This is caused by the increased path length due to multiple scattering in the clouds, which results in a higher probability for absorption of photons by water vapor. 

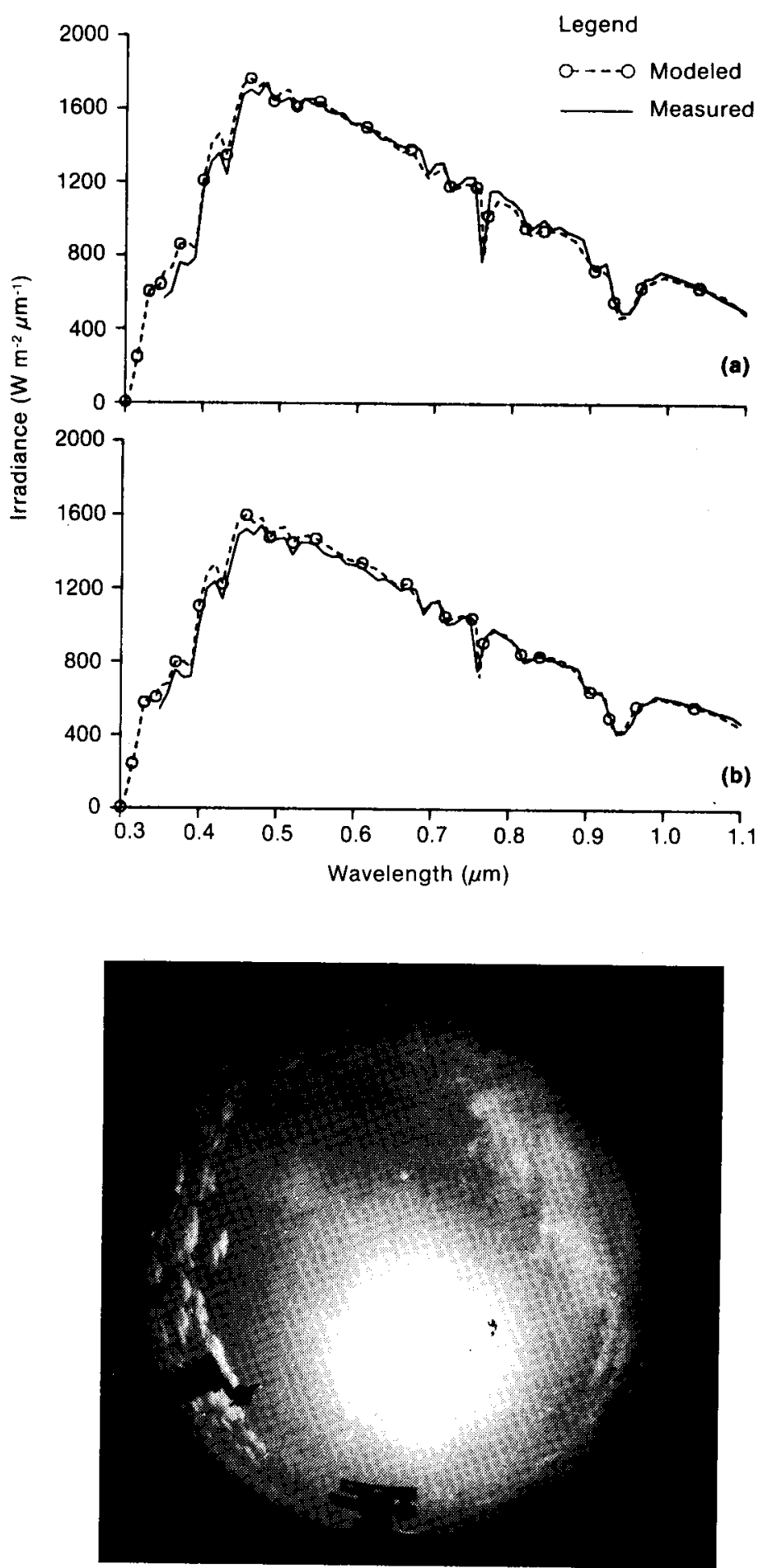

Figure 4-1. Case 1. Comparison of Modeled and Measured Global-Normal (a) and Global-Horizontal (b) Spectral Solar Irradiance, and Photograph of Sky Conditions (solar zenith angle $=28.9^{\circ}$, relative optical air mass $=1.14$ ) 

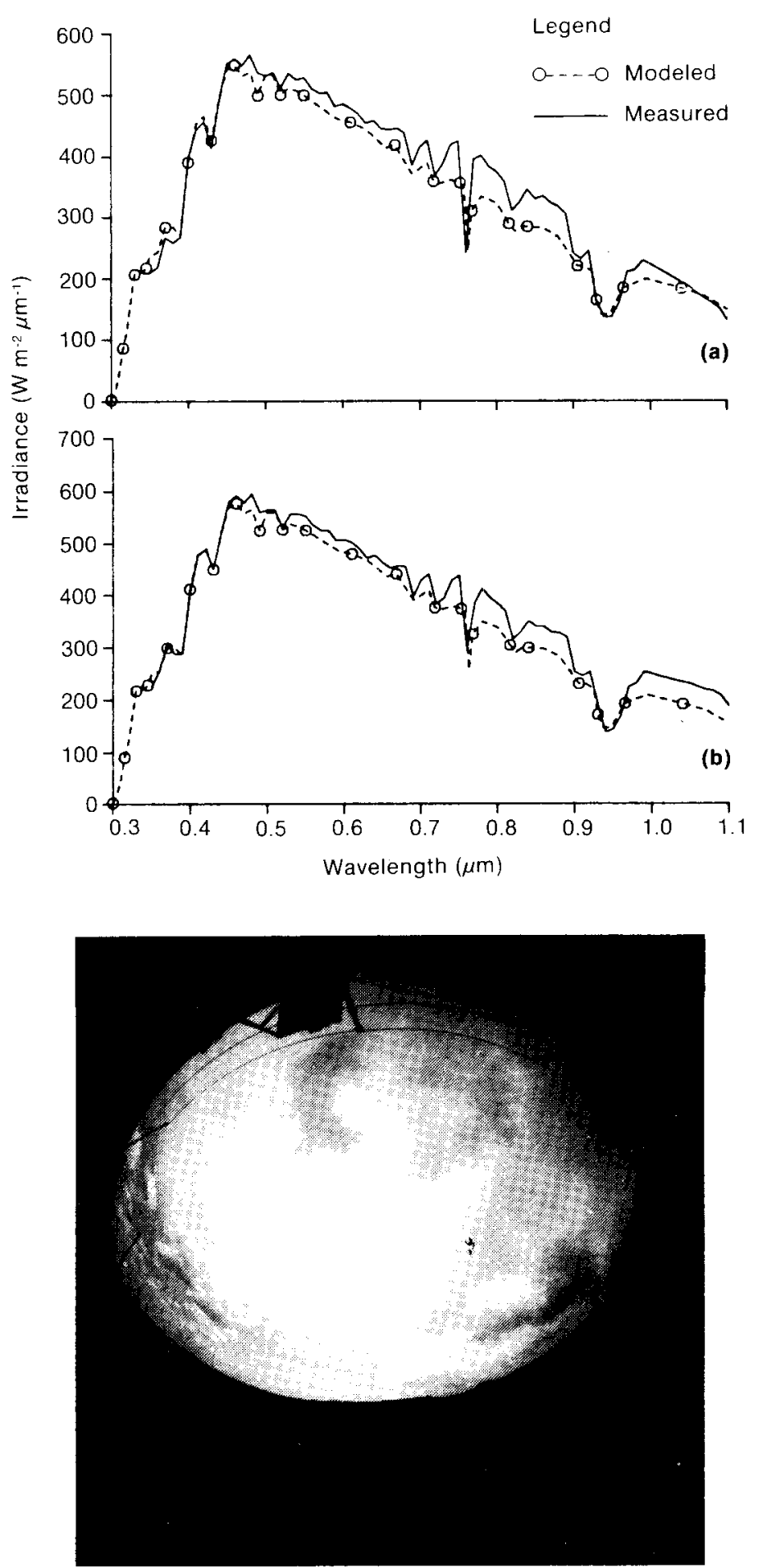

Figure 4-2. Case 2. Comparison of Modeled and Measured Global-Normal (a) and Global-Horizontal (b) Spectral Solar Irradiance, and Photograph of Sky Conditions ( relative optical air mass $=1.15$ ) 

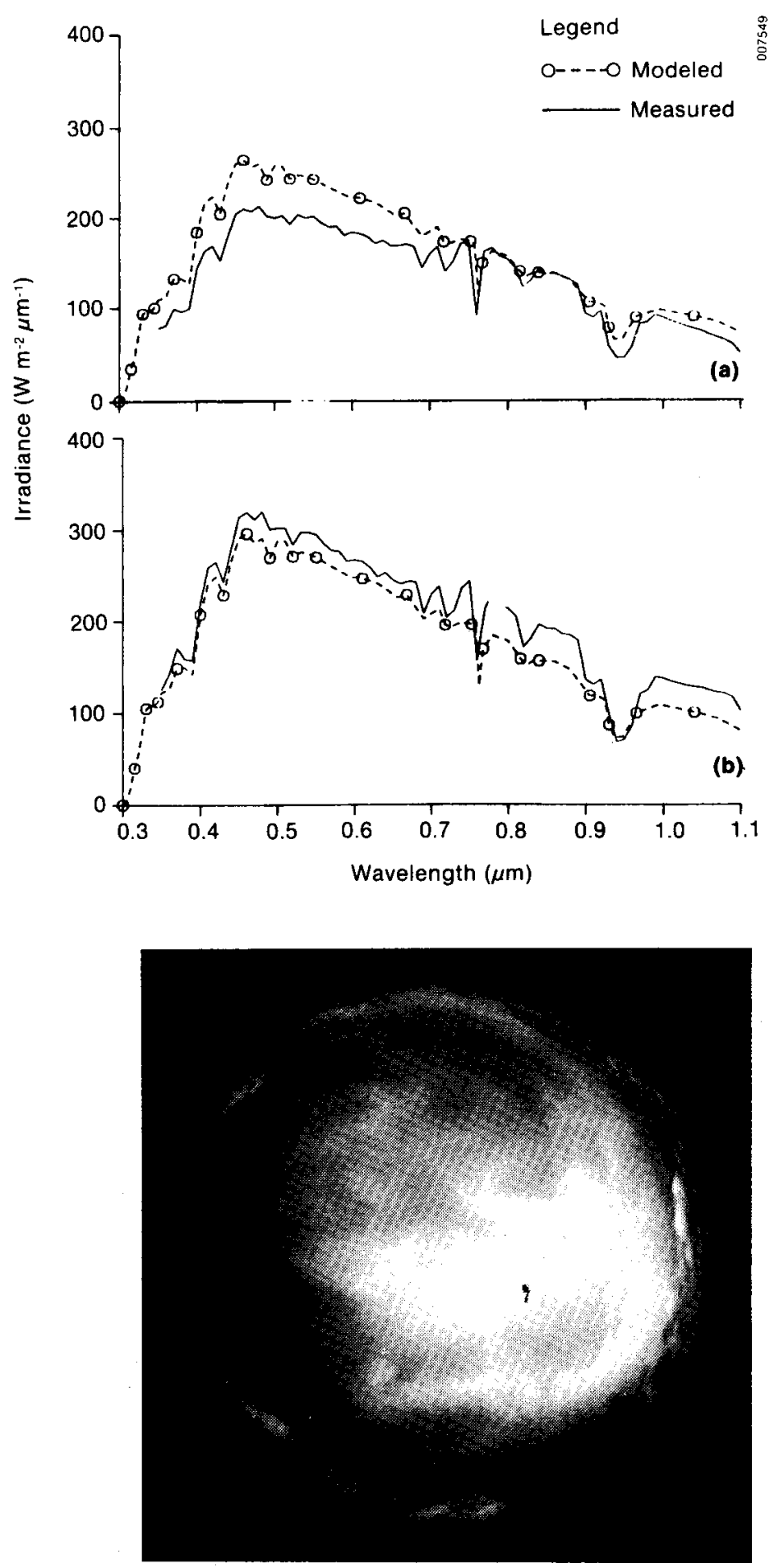

Figure 4-3. Case 3. Comparison of Modeled and Measured Global-Normal (a) and Global-Horizontal (b) Spectral Solar Irradiance, and Photograph of Sky Conditions ( solar zenith angle $=43.7^{\circ}$, relative optical air mass $=1.38$ ) 

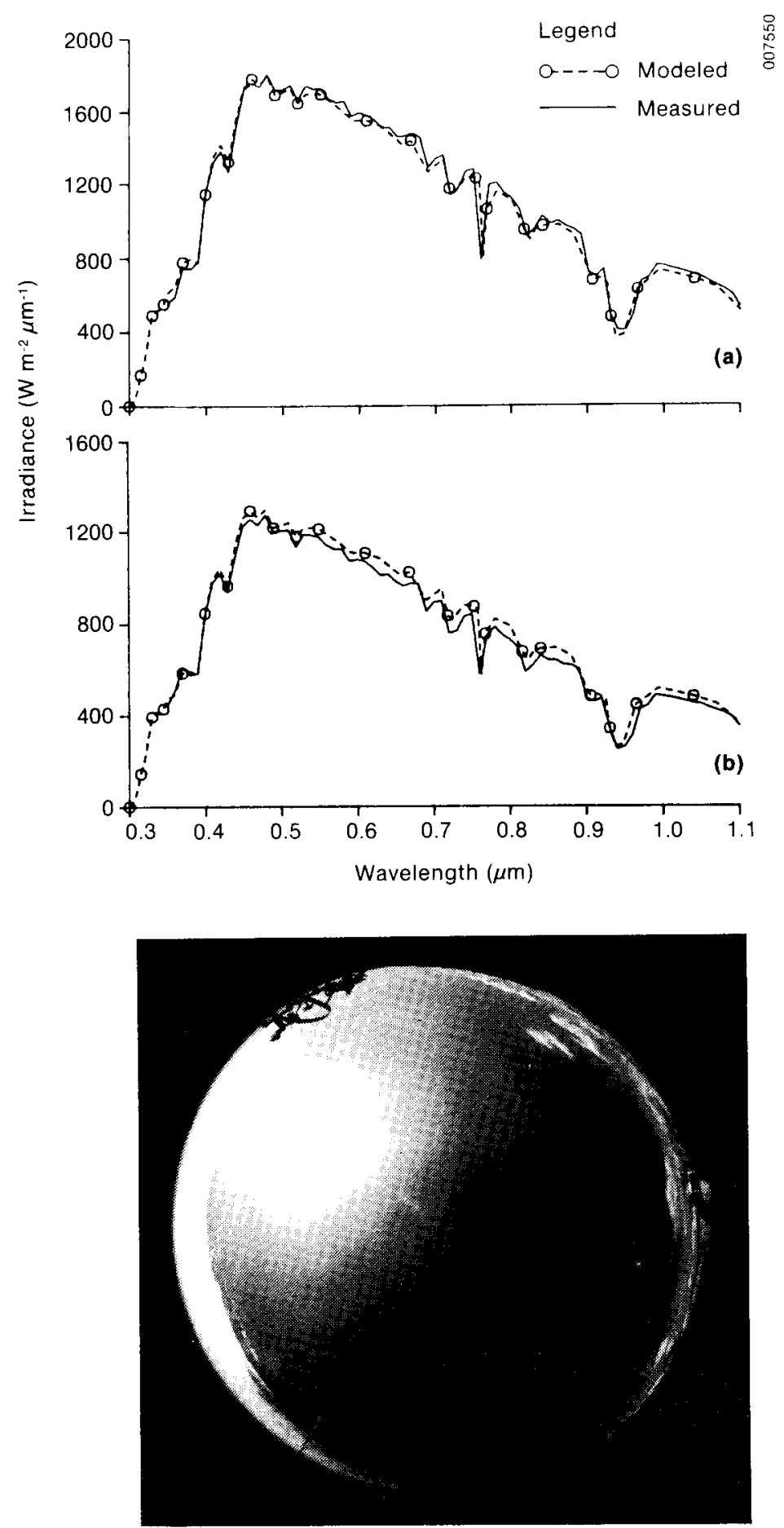

Figure 4-4. Case 4. Comparison of Modeled and Measured Global-Normal (a) and Global-Horizontal (b) Spectral Solar Irradiance, and Photograph of Sky Conditions (solar zenith angle $=44.1^{\circ}$, relative optical air mass $=1.39$ ) 


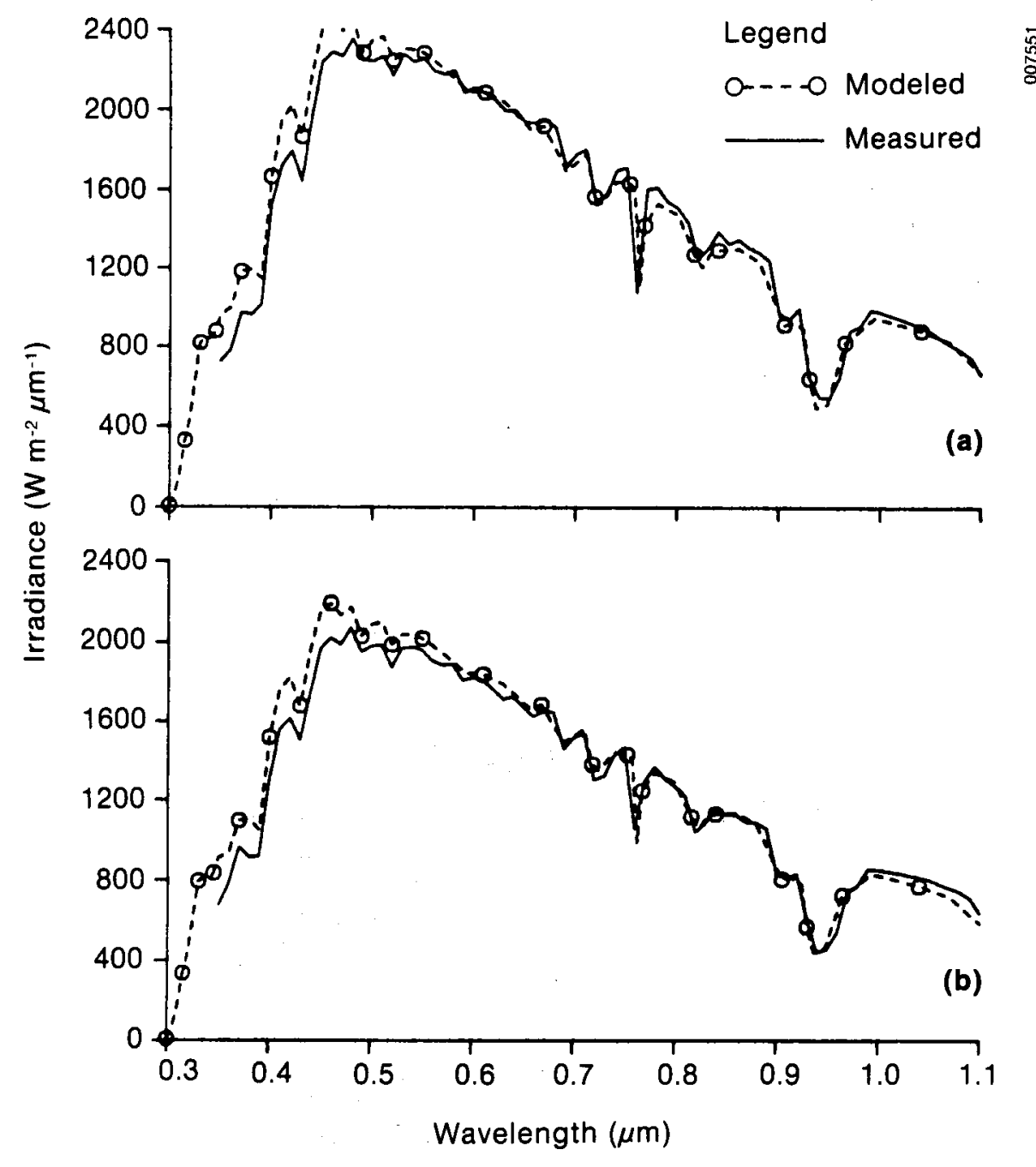

Figure 4-5. Case 5. Comparison of Modeled and Measured Global-Normal (a) and Global-Horizontal (b) Spectral Solar Irradiance (solar zenith angle $=27.9^{\circ}$, relative optical air mass $=1.13$ ) 

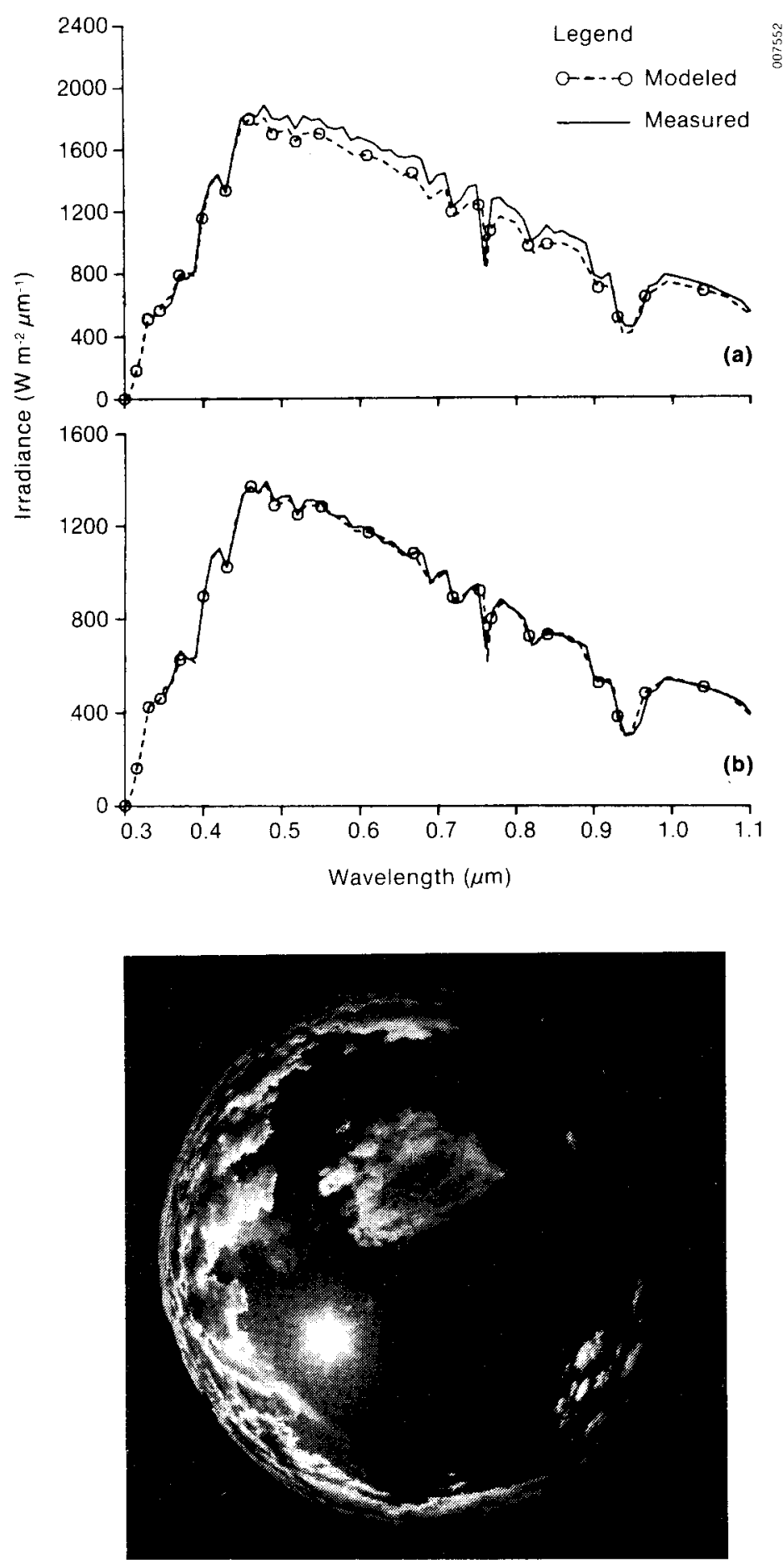

Figure 4-6. Case 6. Comparison of Modeled and Measured Global-Normal (a) and Global-Horizontal (b) Spectral Solar Irradiance, and Photograph of Sky Conditions (solar zenith angle $=40.6^{\circ}$, relative optical air mass $=1.32$ ) 

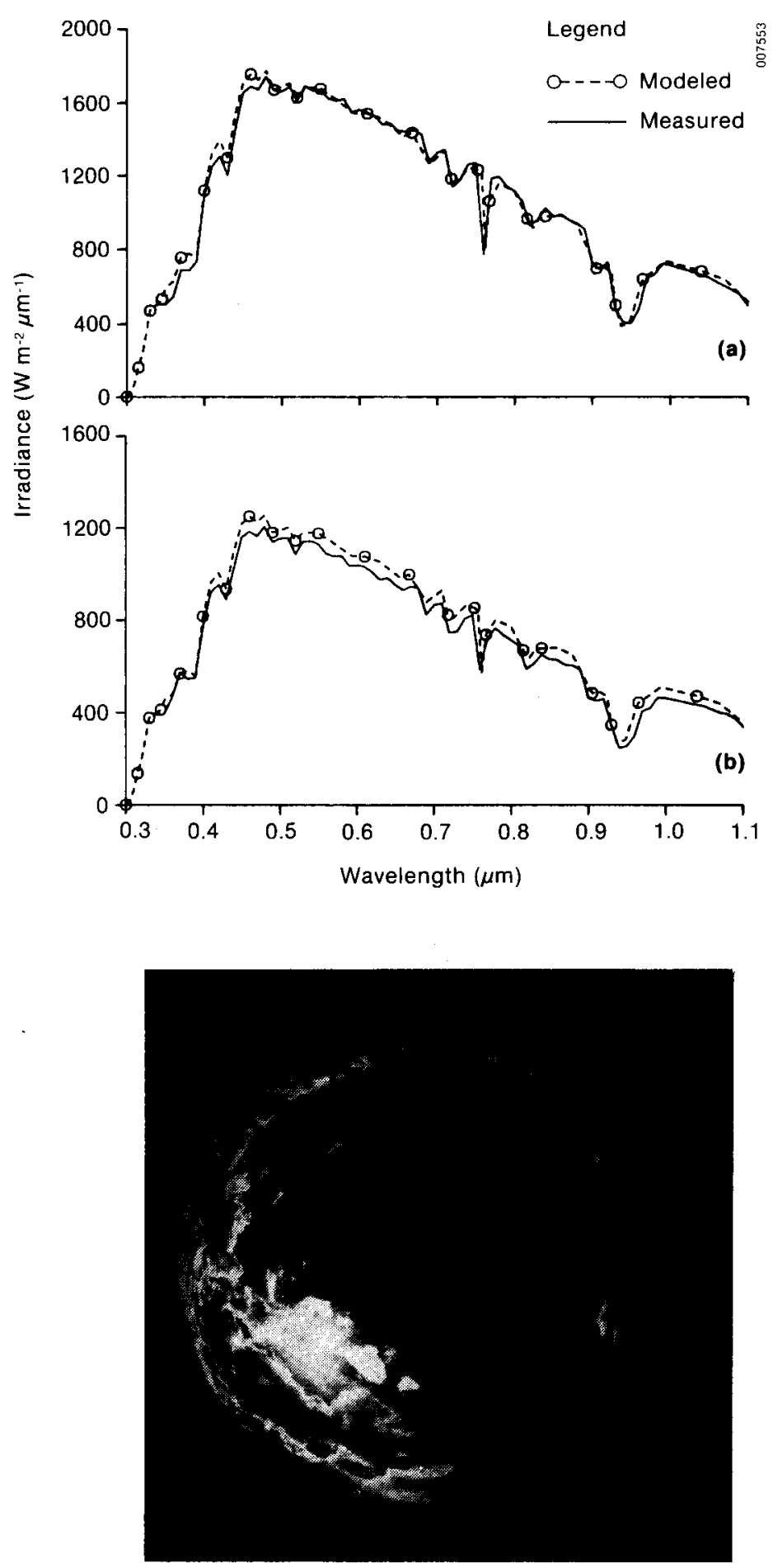

Figure 4-7. Case 7. Comparison of Modeled and Measured Global-Normal (a) and Global-Horizontal (b) Spectral Solar Irradiance, and Photograph of Sky Conditions (solar zenith angle $=45.4^{\circ}$, relative optical air mass $=1.42)$ 


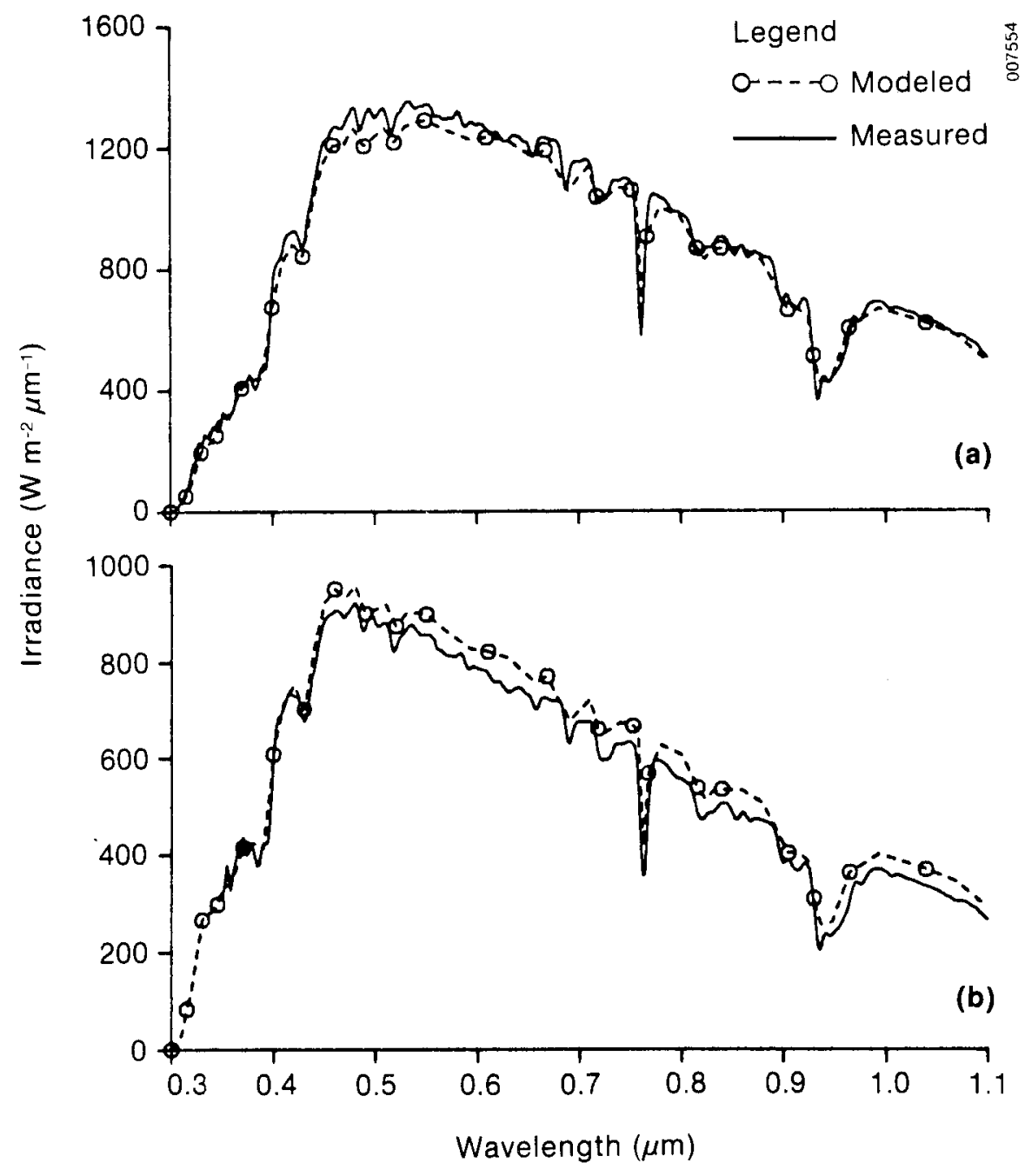

Figure 4-8. Case 8. Comparison of Modeled and Measured Direct-Normal (a) and Global-Horizontal (b) Spectral Solar Irradiance (solar zenith angle $=56.0^{\circ}$, relative optical air mass $=1.78$ ) 

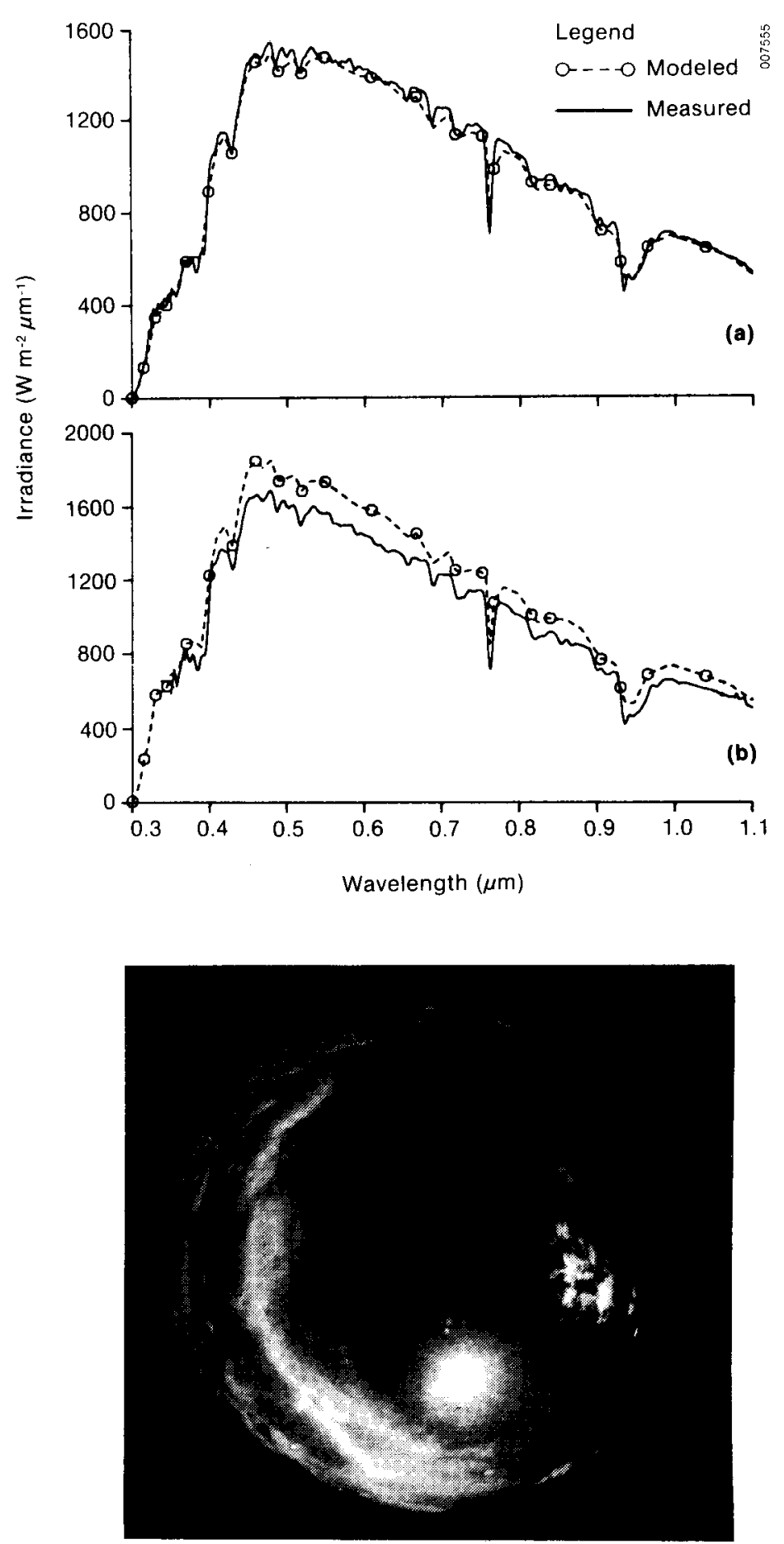

Figure 4-9. Case 9. Comparison of Modeled and Measured Direct-Normal (a) and Global-Normal (b) Spectral Solar Irradiance, and Photograph of Sky Conditions (solar zenith angle $=28.0^{\circ}$, relative optical air mass $=1.13$ ) 

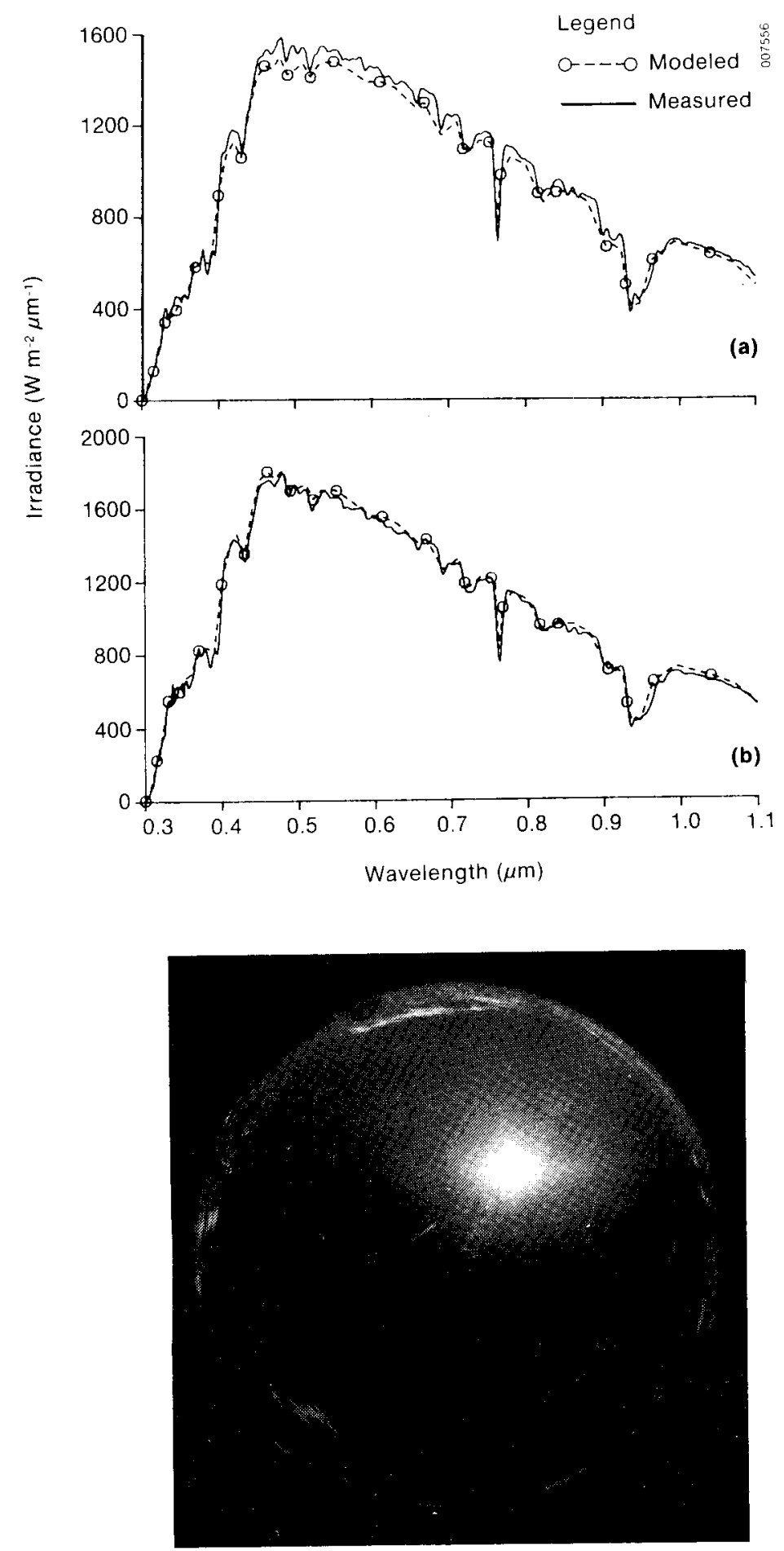

Figure 4-10. Case 10. Comparison of Modeled and Measured Direct-Norma1 (a) and Global-Normal (b) Spectral Solar Irradiance, and Photograph of Sky Conditions (solar zenith angle $=32.8^{\circ}$, relative optical air mass $=1.19$ ) 

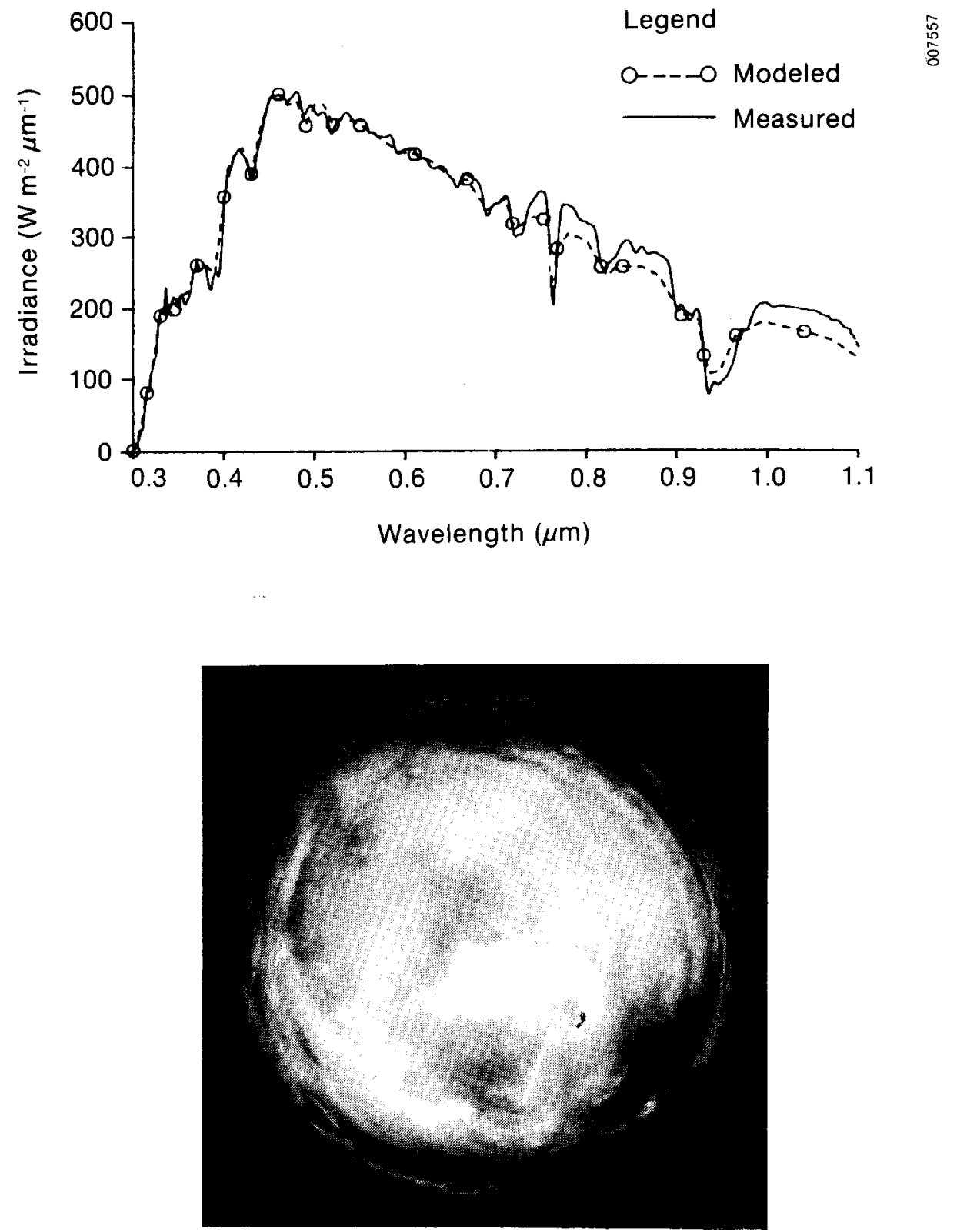

Figure 4-11. Case 11. Comparison of Modeled and Measured Global-Normal Spectral Irradiance, and Photograph of Sky Conditions (solar zenith angle $=30.7^{\circ}$, relative optical air mass $=1.16$ ) 

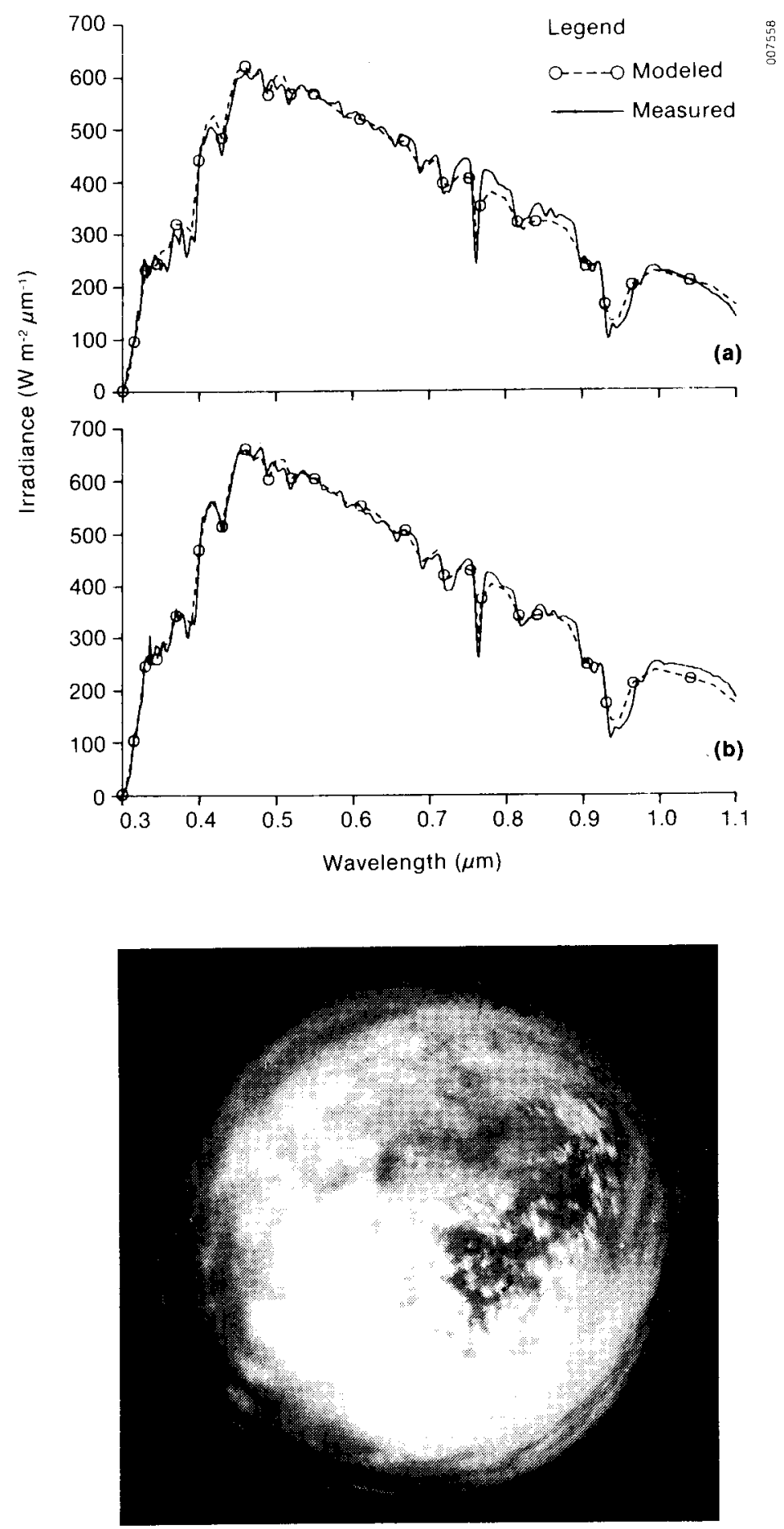

Figure 4-12. Case 12. Comparison of Modeled and Measured Global-Normal (a) and Global-Horizontal (b) Spectral Solar Irradiance, and Photograph of Sky Conditions (solar zenith angle $=34.5^{\circ}$, relative optical air mass $=1.21$ ) 

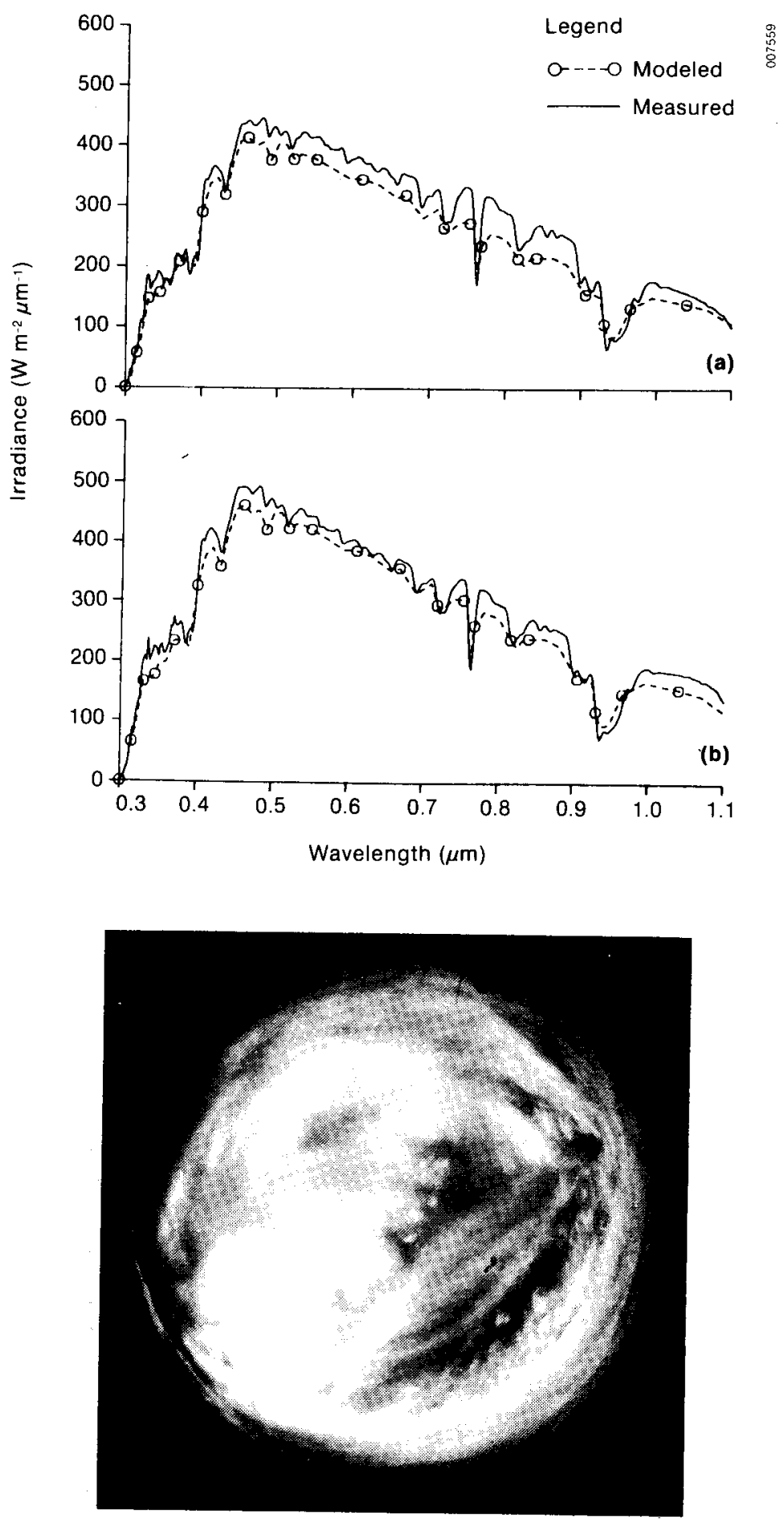

Figure 4-13. Case 13. Comparison of Modeled and Measured Global-Normal (a) and Global-Horizontal (b) Spectral Solar Irradiance, and Photograph of Sky Conditions (solar zenith angle $=43.9^{\circ}$, relative optical air mass $=1.39$ ) 

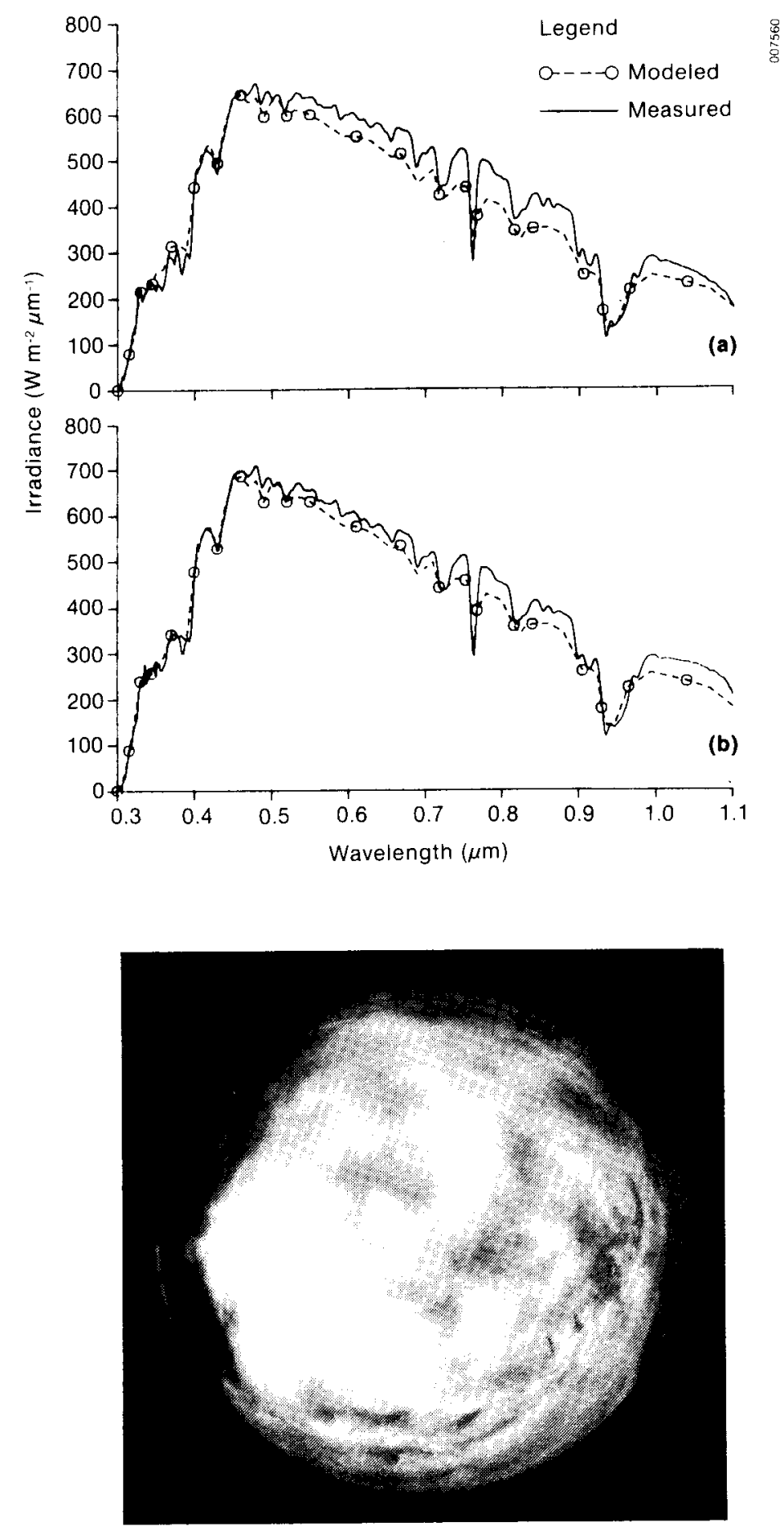

Figure 4-14. Case 14. Comparison of Modeled and Measured Global-Normal (a) and Global-Horizontal (b) Spectral Solar Irradiance, and Photograph of Sky Conditions (solar zenith angle $=48.4^{\circ}$, relative optical air mass $=1.50$ ) 


\subsection{DISCUSSION}

We have attempted to develop a simplified cloud-cover modifier for SPCTRAL2 that accounts for the integrated effects of cloud cover on spectral irradiance. This simple approach was taken for two reasons. First, it is difficult to model the complex relationships and interactions among solar radiation and cloud properties such as shape, size, and composition. Second, if a complex model is developed, it is difficult to obtain the detailed data on cloud properties needed to verify or use the model [12].

We realize the 1 imitations of our simple-model approach, some of which follow:

- It does not account for differences in spectral-irradiance distribution due to different types of clouds. We are assuming that the only available "cloud-cover" information is atmospheric transmittance (determined from GH and DN broadband-irradiance measurements).

- It does not account for the increased water path length due to clouds. This affects the normalization step since the measured broadband irradiance values include the impact of reduced irradiance caused by absorption in the water-absorption bands.

- Turbidity must be estimated from measurements under cloudless-sky conditions near the cloudy period. Since the change from cloudless to cloudy skies indicates unstable atmospheric conditions, this extrapolation of the turbidity value may not be valid. The normalization that is applied when transmittance under cloudy skies differs by more than $5 \%$ from cloudless-sky conditions will compensate for the intensity differences due to error in turbidity, but this will not account for spectral effects.

- The cloud modifier does not account for spectral effects of multiple reflections between the cloud base and the ground, which could be significant when the ground albedo is high (for example, when the ground is snow-covered). The normalization procedure will account for the impacts that these multiple reflections have on total irradiance, but it will not account for spectral effects.

The two spectral modifiers give closer agreement between modeled and measured data by increasing irradiance in the region between 0.30 and $0.926 \mu \mathrm{m}$. Since the modeled data are normalized to a broadband-irradiance value before the spectral corrections are made, there should be a corresponding decrease in spectral irradiance beyond $1.1 \mu \mathrm{m}$ if the broadband-irradiance values are correct. We have not verified this through measurements since the spectroradiometer we are using for measurements has a wavelength 1 imit of $1.1 \mathrm{\mu m}$.

All of the results must be examined with respect to the broadband- and spectral-irradiance measurement uncertainty $[14,15]$. When the cloud-cover modifier is applied, the modeled spectra are normalized to the broadband $\mathrm{GH}$ and DN measured values, which have uncertainty 1 imits of $\pm 2.7 \%$ and $\pm 1.3 \%$, respectively. The spectral modifiers result in closer agreement between modeled and measured data, but the significance and accuracy must be evaluated with respect to the uncertainty in spectral irradiance for different spectral regions, as shown in Table 5-1. Much effort is required to determine uncertainty limits for the measurements. 
Table 5-1. Measurement Uncertainty for Cloudless-Sky Conditions $(\boldsymbol{Z})$

\begin{tabular}{lcccc}
\hline \multirow{2}{*}{ Irradiance } & \multicolumn{4}{c}{ Wavelength $(\mu \mathrm{m})$} \\
\cline { 2 - 5 } & 0.35 & 0.65 & 0.90 & 1.30 \\
\hline Global Horizontal & 10.7 & 10.0 & 12.3 & 11.9 \\
Global Normal & 6.4 & 7.0 & 9.6 & 15.8 \\
Direct Normal & 5.5 & 5.4 & 9.5 & 12.8 \\
\hline
\end{tabular}

The uncertainty values are based on laboratory calibrations against National Bureau of Standards (NBS) traceable standard irradiance lamps, and outdoor tests of the integrating sphere response (in global-irradiance cases) with the direct-beam component present. The global-horizontal uncertainty values include an $8.5 \%$ directional bias error that is not applicable under completely diffuse sky conditions. Uncertainty limits for anisotropic diffuse conditions or completely diffuse conditions are under investigation. The values in this table represent our most conservative estimates to date. Further data and analysis are required to fully characterize all sources of error for particular measurement configurations. Accuracy of the measurements is critical for comparisons with modeled data. 


\subsection{SUMMARY AND CONCLUSIONS}

Our objective is to develop and evaluate a simple cloud-cover modification to the SERI model for cloudless-sky spectral solar irradiance (SPCTRAL2). Our approach was to begin with the hypothesis that clouds act as a wavelengthindependent filter on the cloudless-sky spectral distributions and then use comparisons of modeled and measured data to empirically derive spectral modifiers, if necessary. The only two additional inputs to SPCTRAL2 that are required to implement such a modifier are measurements of global-horizontal (GH) and direct-normal (DN) broadband irradiance.

Based on comparisons of modeled and measured data, we incorporated a cloudcover modifier into SPCTRAL2 so that the model accomplishes the following:

- Calculates cloudless-sky GH and DN spectral irradiance

- Normalizes the modeled cloudless-sky, GH and DN spectral-irradiance to broadband-irradiance measurements if the integral of the modeled GH spectrum differs by more than $5 \%$ from the broadband value

- Calculates spectral irradiance on the collector surface (i.e., converts to irradiance on a tilted surface if appropriate)

- Applies two spectral corrections to the calculated diffuse irradiance if the normalization step is invoked.

In general, when a strong direct-beam component is present (under cloudlesssky or partly cloudy conditions) the cloud-cover modification (normalization and spectral corrections) is not applied. In the two cases where the direct beam was present and the cloud-cover modification was invoked, the agreement between modeled and measured data was very good between 0.55 and $1.1 \mu \mathrm{m}$, although the spectral correction below $0.55 \mu \mathrm{m}$ caused the modeled values to be higher than the measured values. It is possible that we should include another criterion for normalization that is based on the ratio of measured to modeled direct-beam irradiance. When the cloud-cover modification was not invoked, the modeled DN spectrum is slightly lower than measured in the visible region, which may be caused by circumsolar radiation that is not included in the modeled DN data.

In cases where the cloud-cover modification was applied, the agreement between modeled and measured data is generally within the measurement uncertainty of $5 \%-10 \%$ up to $0.7 \mathrm{\mu m}$, but can deviate by as much as $15 \%-20 \%$ beyond $0.7 \mu \mathrm{m}$ in some cases. The difference is more pronounced for GN than for GH cases, which may indicate a relationship to spectral ground albedo. However, in some cases (for example, case 12), the agreement between modeled and measured data is within the measurement uncertainty of $5 \%-10 \%$.

Because of the limitations of our analyses/approach, as stated in the previous section, the cloud-cover modifier given in this report is considered to be preliminary. This data set is not large enough to compute comprehensive error statistics, but it allows us to examine the general form of a cloud-cover spectral transmission function. Although our normalization approach is reasonable, we need to analyze more data to refine and investigate the spectral corrections of the proposed cloud-cover modifier. We expect to produce a final cloud-cover modifier by late 1987 . 


\subsection{FUTURE WORK}

The results of our evaluation of the cloud-cover modification suggest the following avenues for further research.

- We will collect additional data for a range of cloud types and thicknesses and then derive a cloud-cover spectral transmission function. If resources permit, we will use radiative transfer models to derive theoretical transmission functions for different clouds for comparison with the measurements. Error statistics will be computed for the transmission function.

- If we continue to observe a consistent bias in the measured data to be greater than modeled data in the region beyond $0.55 \mu \mathrm{m}$ (especially 0.7 to $1.1 \mu \mathrm{m})$ under overcast conditions, we will adjust the model accordingly. Preliminary analysis of modeled data suggests that the effect may be due to multiple reflections between the ground and cloud bases, with high spectral ground reflectance in this region. We will evaluate the impacts of spectral albedo on modeled spectra.

- If resources permit, we will acquire spectral measurements beyond $1.1 \mu m$ to examine the impacts of normalization and spectral modifiers over the entire spectrum.

- We will continue to perform error analysis and determine uncertainty limits for the measurements that are used for comparison with modeled data. This uncertainty determines the 1 imits to which model modifications are valid and significant. 


\subsection{REFERENCES}

1. Bird, R., and C. Riordan, Simple Solar Spectral Model for Direct and Diffuse Irradiance on Horizontal and Tilted Planes at the Earth's Surface for Cloudless Atmospheres, SERI/TR-215-2436, Golden, CO: Solar Energy Research Institute, Dec. 1984.

2. Bird, R. E., and C. Riordan, "Simple Solar Spectral Model for Direct and Diffuse Irradiance on Horizontal and Tilted Planes at the Earth's Surface for Cloudless Atmospheres," Journal of Climate and Applied Meteorology, Vol. 25, No. 1, Jan. 1986, pp. 87-97.

3. Solar Energy Research Institute, Photovoltaics and Insolation Measurements Workshop Proceedings; June 30 - July 3, 1985, Vail, Colorado, SERI/CP-215-2773, Golden, CO: Solar Energy Research Institute.

4. Hulstrom, R. L., Final Report of the Amorphous Silicon Measurements Task Force, SERI/SP-215-2784, Golden, CO: Solar Energy Research Institute, Aug. 1985.

5. Hulstrom, R. L., Resource Assessment Project - User Needs Survey Results, SERI/PR-215-2981, Golden, CO: Solar Energy Research Institute (in progress).

6. Bird, R. E., "A Simple Solar Spectral Model for Direct-Normal and Diffuse Horizontal Irradiance," Solar Energy, Vo1. 32, No. 4, 1984, pp. 461-471.

7. Riordan, C. J., Comparisons of Modeled and Measured Spectral Solar Irradiance Data, SERT/TR-215-2809, Golden, CO: Solar Energy Research Institute, Feb. 1986.

8. Deirmendjian, D., Electromagnetic Scattering on Spherical Polydispersions, New York: American Elsevier Publishing Company, Inc., 1969.

9. Guzzi, R., O. Vittori, and C. Tomasi, "Sun Spectra Through Optically Thin Clouds," Journal of the Atmospheric Sciences, Vol. 31, No. 1, 1974, pp. $251-254$.

10. Feigelson, E. M., Radiation in a Cloudy Atmosphere, Boston, MA: D. Reidel Publishing Company, 1984, p. 61.

11. Hulstrom, R. L., R. E. Bird, T. W. Cannon, T. L. Stoffel, C. Riordan, and V. Szwarc, SERI Insolation Research FY 1982 Annual Report, SERI/PR-215-1725, Golden, CO: Solar Energy Research Institute, Sept. 1982 .

12. Powel1, M. Jr., A Simple Solar, Spectral Model for Studying the Effects of Cloud Cover and Surface Albedo on the Incoming Solar Radiation, Ph.D. Dissertation, Ann Arbor, MI: The University of Michigan, 1986. 
13. Riordan, C. J., and R. L. Hulstrom, The SERI Resource Assessment Project's Plan for Collecting Spectral-Solar-Irradiance Data, SERI/TR-2152948, Golden, CO: Solar Energy Research Institute, Dec. 1986.

14. Myers, D., Measurement Uncertainty for the SERI Spectral-Solar-Irradiance Data Base Project, Golden, CO: Solar Energy Research Institute (in progress).

15. Riordan, C., Sensitivity Analyses of SPCTRAL2 and Implications for Further Spectral Irradiance Measurements and Model Improvement/Validation Verification, Golden, CO: Solar Energy Research Institute (in progress). 


\begin{tabular}{|c|c|c|c|}
\hline $\begin{array}{l}\text { Document Control } \\
\text { Page }\end{array}$ & $\begin{array}{l}\text { 1. SERI Report No. } \\
\text { SERI/TR-215-3038 }\end{array}$ & 2. NTIS Accession No. & 3. Recipient's Accession No. \\
\hline \multirow{2}{*}{\multicolumn{3}{|c|}{$\begin{array}{l}\text { 4. Title and Subtitle } \\
\text { Investigation of a Cloud-Cover Modification to SPCTRAL2, } \\
\text { SERI's Simple Mode1 for Cloudless-Sky Spectral Solar } \\
\text { Irradiance }\end{array}$}} & $\begin{array}{l}\text { 5. Publication Date } \\
\text { June } 1987\end{array}$ \\
\hline & & & 6. \\
\hline \multicolumn{3}{|c|}{$\begin{array}{l}\text { 7. Author(s) } \\
\text { R.E. Bird, C.J. Riordan, D.R. Myers }\end{array}$} & 8. Performing Organization Rept. No \\
\hline \multirow{2}{*}{\multicolumn{3}{|c|}{$\begin{array}{l}\text { 9. Performing Organization Name and Address } \\
\text { Solar Energy Research Institute } \\
\text { A Division of Midwest Research Institute } \\
\text { 1617 Cole Blvd. } \\
\text { Golden, Colorado } 80401-3393\end{array}$}} & $\begin{array}{l}\text { 10. Project/Task/Work Unit No. } \\
6004.10\end{array}$ \\
\hline & & & $\begin{array}{l}\text { 11. Contract (C) or Grant (G) No. } \\
\text { (C) } \\
\text { (G) }\end{array}$ \\
\hline \multirow{2}{*}{\multicolumn{3}{|c|}{ 12. Sponsoring Organization Name and Address }} & $\begin{array}{l}\text { 13. Type of Report \& Period Covered } \\
\text { Technical Report }\end{array}$ \\
\hline & & & $\sqrt{14 .}$ \\
\hline
\end{tabular}

15. Supplementary Notes

16. Abstract (Limit: 200 words) This report summarizes the investigation of a cloud-cover modification to SPCTRAL2, SERI's simple model for cloudless-sky, spectral solar irradiance. Our approach was to develop a modifier that relies on commonly acquired meteorological and broadband-irradiance data rather than detailed cloud properties that are generally not available. The method was to normalize modeled, cloudless-sky, spectral irradiance to a measured broadband-irradiance value under cloudy skies, and then to compare the normalized, modeled data with measured spectral-irradiance data to empirically derive spectral modifiers that improve the agreement between modeled and measured data. Results indicate the possible form of the spectral corrections; however, we must analyze additional data to develop a spectral transmission function for cloudy-sky conditions.

17. Document Anaiysis

a. Descriptors solar radiation ; insolation ; solar irradiance ; resource assessment

b. Identifiers/Open-Ended Terms

c. UC Categories 62,63

18. Availability Statement

National Technical Information Service

U.S. Department of Commerce

5285 Port Royal Road

Springfield, Virginia 22161

\begin{tabular}{|c|c|}
\hline & $\begin{array}{l}\text { No. of Pages } \\
40\end{array}$ \\
\hline 20. & Price \\
\hline & $\mathrm{A} 03$ \\
\hline
\end{tabular}

